\title{
Complexities of Online Thesis Supervision during the Covid-19 Pandemic: EFL Lecturers' Perceptions
}

\author{
Lastika Ary Prihandoko ${ }^{1}$, Djatmika Djatmika ${ }^{2 *}$, and Joko Nurkamto ${ }^{3}$
}

\author{
${ }^{1}$ Universitas Musamus Merauke \\ ${ }^{2,3}$ Universitas Sebelas Maret \\ *Corresponding author. Email: djatmika@staff.uns.ac.id
}

\begin{abstract}
The Covid-19 outbreak has resulted in the transformation of EFL undergraduate thesis supervision from offline to online, bringing with it its inherent complexities. Hence, this qualitative study sought to investigate the complexities associated with online EFL thesis supervision from the lecturers' perspective. The complexities in this study were conceptually categorized as problems and solutions. The participants were purposefully chosen. They were 30 lecturers from two universities in Central Java and Papua. The data were collected using interviews and analyzed using an interactive model. The findings revealed a variety of problems with online thesis supervision, such as facing difficulties in going along with the shift from offline to online thesis supervision, having ineffective interactions between lecturers and students, having less time available to constantly access online media, being hampered in the field data collection process because many schools students had targeted to collect their data held online learning, and suffering from a decrease in students' motivation. To cope with such problems, there were some solutions offered by lecturers. The lecturers asked students to remind them of the online thesis supervision schedule, making active use of communication technology, assisting students in interacting with authorized parties of students' research objects, and reorienting students' research data collection. Further research is expected to focus on a similar problem to that addressed in this study, but with a larger sample size drawn from various provinces throughout Indonesia. Such studies may be beneficial for extending our current findings and adding to the body of knowledge regarding online thesis supervision in the Indonesian context.
\end{abstract}

\section{Keywords: EFL undergraduate thesis, online thesis supervision, problems and solutions}

\section{INTRODUCTION}

The global pandemic of Covid-19 has created complexities for either lecturers or students in terms of all academic activities at universities, where such activities must be conducted online [1]. The preceding is true in a number of countries, including Indonesia. Such an offline-to-online transition is not fluid in nature, as two factors, technological competence and facilities, will inevitably become potential roadblocks to the successful continuation of online educational activities, such as curriculum administration, learning, and thesis supervision. For example, when it comes to implementing online learning in Indonesian universities, Pramana et al. noted that the most frequently used platform is the Whatsapp application, which is the simplest social media application, and that weak internet signals frequently impair learning effectiveness [2]. Their study demonstrated unequivocally that technological competence and infrastructure are at the heart of online learning problems. These problems have also been confirmed by Efriana's study [3].
Regardless of the covid-19 problem, over the last five years, numerous studies have been conducted at various levels of educational institutions in various countries on various topics related to online learning, elearning, and distant learning, but very few have addressed the problem of online thesis supervision. For instance, Huang's study depicted online learning problems in terms of teachers' roles, revealing that students do not perceive teachers' cognitive, affective, and managerial roles as expected [4]. Another study described online learning difficulties as a result of conflicting expectations between teachers and students [5]. The other research reaffirmed the critical role of teachers' active responses in resolving online learning problems [6]. Additionally, studies undertaken by Barclay et al. and Thongsri et al. emphasized the importance of technological facilities and competence as the determinants of ability to deal with online learning problems [7], [8]. Nonetheless, prior research on the complexities of online thesis supervision is scarce in the context of universities. Until now, the 
majority of studies on the complexities of thesis supervision has been conducted in an offline mode. Such studies revealed that insufficient supervision time and structural efficiency of supervision become problems in thesis supervision [9]; students' negative perceptions of thesis supervision are a result of unclear interventions and complete control from lecturers [10]; the distance between lecturers and students has an effect on the effectiveness of interactions during thesis supervision [11]

As mentioned previously, very few or no prior studies have addressed the complexities associated with online thesis supervision. Our study seeks to fill this void in the literature. Triggered by the global and national impact of the covid-19 on the offline-to-online transformation of all academic activities at universities, and prompted by the literature gap that no prior studies on thesis supervision have been conducted in the context of online thesis supervision, the current study seeks to address the complexities of online EFL undergraduate thesis supervision. In this study, we define complexity as the interactions between the existing problems and the proposed solutions.

\section{LITERATURE REVIEW}

\subsection{EFL Undergraduate Thesis and Thesis Supervision}

The EFL undergraduate thesis is a form of academic writing that requires research and addresses problems or variables in the discourses of EFL education and linguistics. Undergraduate theses are the final stage that undergraduate students must complete before receiving their bachelor's degrees [12]. A thesis, as a type of academic writing, is a form of interactive communication between the writer and readers in which the writer discusses a problem in detail using data with the goal of providing the readers with accurate information. As mentioned previously, academic writing is challenging to master because the stages require intellectual activities such as brainstorming ideas, planning, sketching a conceptual framework for what to write, writing drafts, correcting, and revising [13]. Not only should an academic writer be accurate and fluent in his or her use of academic terms, collocations, phrases, and grammar [14], but he or she should also be capable of mapping references to the discourse under consideration [15] and constructing arguments with a clear and understandable idea organization [16]. According to $\mathrm{Wu}$ et al., undergraduate students go through six phases when writing a thesis: choosing the orientation of the research area through discussions with lecturers, determining the research topic, conducting the research project, writing the first draft of the thesis, revising and finalizing the thesis [17]. A thesis is composed of six general components: an introduction, a literature review, a research methodology, results or findings and discussion, conclusions and recommendations, and references. These elements each have their own distinct moves [18]. Each stage and component of the thesis writing process varies in terms of complexity and difficulty [19]. As a result, students require guidance from experienced lecturers who are adept at a variety of supervision styles and strategies. The lecturery style, or how a lecturer interacts with and responds to students during the thesis supervision process, has a significant impact on the quality of students' work [20].

Apart from being committed and enthusiastic about their fields of study, undergraduate students must participate in effective thesis supervision processes in order to complete their theses on time [21]. Thesis supervision is defined as collaborative, interactive, and complex relationships between lecturers and students that incorporate emotional and cognitive dimensions in order to assist students in successfully completing their theses [22], [23]. Effective thesis supervision is characterized by effective communication processes and supervision patterns that adapt to students' needs [22]. There are two dimensions to the relationship between students and lecturers. The first dimension is concerned with imparting knowledge and composing guidelines. The second dimension is concerned with the content of the research [24]. Lecturers should ideally be able to make decisions that are centered on the students' affective dimensions, such as empowering students to construct arguments and attending to their social needs; decisions that are centered on the students' cognitive dimensions, such as checking and improving students' understanding; and decisions that are centered on the lecturers' cognitive dimensions, such as assessing and improving students' understanding [10].

Given the length of the thesis writing process, the lecturers' patterns of interaction and strategies for responding to students' thesis writing become critical aspects of thesis supervision, as these factors influence the quality of students' theses [20]. Students require effective guidance from their lecturers throughout the process of selecting appropriate research topics to writing reports on the findings of their research projects. Thus, thesis supervision requires a balance of academic knowledge and skilled management on the part of lecturers, who must also be capable of developing positive, personal, and professional relationships with students [21]. Lecturers are responsible for controlling the frequency of communication with students, taking their schedules into account, offering advice, and providing effective feedback. Lecturers are expected to be able to perform a variety of roles during supervision processes, including acting as problem solvers to stimulate students' cognitive development, providing emotional support, and mentoring students to increase their effectiveness in writing theses [22].

The global phenomenon of the Covid-19 outbreak, which has an effect on learning's transition from offline to online modes, also has an effect on thesis supervision's transition from offline to online modes. Naturally, this has created difficulties for lecturers and students, in addition to the already complex processes of thesis supervision. Nonetheless, online supervision is conceivable, and it is viewed as an effective solution at 
some point, where interactions between lecturers and students are mediated by technological devices such as computers, email, and various social media applications [25]. If online thesis supervision is well-organized, it can be more efficient in terms of time management [26]. Almeatani's et al. research, for example, echoed the transition of thesis supervision to an online mode. They attempted to create a controlled platform to facilitate thesis supervision processes in which lecturers and students did not have to meet face to face. The platform was dubbed the mobile thesis supervision system. This platform facilitated students' timely completion of their theses. Students and lecturers were both capable of managing each phase of supervision effectively. Additionally, the platform aided in the electronic documentation of the progress of the thesis. Management parties, lecturers, and students could all review and monitor the platform. Students and lecturers can also access this platform via their mobile devices. Students could jot down any thoughts about thesis supervision that occurred to them at any time or in any location. Additionally, the system aided lecturers in providing pertinent feedback on students' theses [11]. Nasution et al. made a similar effort to develop a platform for thesis supervision [27]. Apart from the efficacy of online thesis supervision, Casado-Lumbreras and Colomo-Palacios explained that online thesis supervision processes are not always smooth, which can contribute to students' negative perceptions. For instance, students may be perplexed by the supervision process, have difficulty comprehending their guided online research projects, be unclear about the roles of lecturers, and have difficulty working on their research projects [28].

\subsection{Problems and Strategies to Deal with Problems in Thesis Supervision}

In thesis supervision processes, lecturers and students all contribute to the existence of problems. In terms of thesis supervision processes, problems typically arise due to insufficient supervision time, an inefficient supervision system, supervision processes that fall short of student expectations, and insufficient facilities for interaction between lecturers and students. Ortiz-Catalan et al. demonstrated that one of the reasons students' theses are of poor quality is a lack of supervision time due to lecturers' busy schedules. Another reason is a dearth of efficient patterns governing thesis supervision processes [29]. Students oftentimes expect well-organized supervision processes from their lecturers and likely have negative perceptions if such desirable supervision processes are not established [10]. As the foregoing, it is critical to meet students' expectations while supervising their theses [10]. Additionally, Almeatani et al. demonstrated that insufficient interaction facilities significantly impair the effectiveness of thesis supervision, and thus their study sought to design a mobile thesis supervision system accessible to students via mobile phones. The thesis supervision mobile system enables lecturers and students to have more effective and efficient interactions and assists students in completing their theses on time [11].

In the case of lecturers, complexities are frequently associated with the inadequacy of lecturers' roles and supervising styles. Students are more likely to be frustrated when their lecturers attempt to constantly give them complete control. Students are denied the opportunity to construct arguments, develop ideas, and be creative in constructing information relevant to the research topics on which they are working [10]. Additionally, Casado-Lumbreras and Colomo-Palacios demonstrated that the acceptability of lecturers' styles has a significant impact on the effectiveness and efficiency of supervision processes. Students who are unfamiliar with their lecturers' styles (e.g., lecturers who combine the style of a mentor with that of a lecturer) frequently become confused and struggle to complete their theses in a timely manner [28].

In terms of students, a number of difficulties encountered during the thesis supervision process are generally related to students' inadequate foreign language skills as a means of accessing international sources, inadequate academic writing knowledge and skills, and low self-efficacy in academic writing skills. Malaga-Toboa et al. conducted an analysis of students' electronic reading sources during the thesis writing process. Their study discovered that the majority of their participants prefer to access publishers' websites in Polish (their mother tongue). This is because students' English abilities limit their ability to absorb information from scientific articles published in international journals, the majority of which are written in English. Inadequate reading resources have been linked to a decline in the quality of students' theses [30]. Following that, Casado-Lumbreras and Colomo-Palacios described several problems arising from the perspective of their student participants. Numerous participants admitted that they lacked the necessary knowledge and skills for writing academic papers. Several participants stressed their lack of confidence in their ability to complete their theses [28].

By their very nature, complexities encountered during the offline or online thesis supervision processes necessitate lecturers' coping strategies. Lecturers' role in transforming students' negative attitudes toward thesis supervision processes into positive ones is critical to the supervision process's continued success [28]. Additionally, lecturers must be capable of utilizing a range of academic and non-academic strategies to assist students with thesis supervision. Casado-Lumbreras and Colomo-Palacios expanded on their study of online thesis supervision by describing several strategies that lecturers use to facilitate and assist students during thesis supervision. Among these strategies are the following: fostering students' active attitudes toward thesis supervision, including decision-making, responsibility, and autonomy; effectively managing supervision time and planning the execution of thesis supervision; stimulating students' motivation; 
stimulating students' mental block management; reducing students' negative emotions; and guiding students in the selection of research [28]. Following that, problems such as limited supervision time and incompatibility of lecturer and student schedules prompted researchers such as Almeatani et al. and Nasution et al. to develop information systems for managing thesis supervision processes [11], [27]. The systems developed are in the form of platforms that can be accessed via lecturers' and students' smartphones, facilitating interaction.

\section{METHOD}

The current study conducted a qualitative investigation into the complexities (problems and solutions) of online thesis supervision as perceived by lecturers. We enlisted lecturers from Java and Papua as the participants. We selected the participants using a purposive sampling technique. To this end, we established some purposive sampling criteria, in which the participants were EFL lecturers with sufficient experience supervising thesis work for EFL undergraduate students. Second, the participants could be contacted easily via online communication. Third, the participants volunteered to participate in this study.

Table 1. Complexities of Online Thesis Supervision

\begin{tabular}{|c|c|c|c|}
\hline No & Problems & No & Solutions \\
\hline 1 & $\begin{array}{l}\text { Still getting acclimated to the shift from an } \\
\text { offline to an online manner of thesis } \\
\text { supervision }\end{array}$ & 1 & $\begin{array}{l}\text { Asking students to remind the supervisors of the } \\
\text { online supervision schedule }\end{array}$ \\
\hline 2 & $\begin{array}{l}\text { Slightly ineffective communication } \\
\text { between the lecturers and students }\end{array}$ & 2 & Making active use of communication technology \\
\hline 3 & $\begin{array}{l}\text { Inability to access internet media on a } \\
\text { consistent basis due to a lack of time }\end{array}$ & 3 & $\begin{array}{l}\text { Helping students to interact with the authorized } \\
\text { parties of students' research objects }\end{array}$ \\
\hline 4 & $\begin{array}{l}\text { Getting stymied for gathering data in the } \\
\text { field }\end{array}$ & \multirow[t]{3}{*}{4} & \multirow[t]{3}{*}{$\begin{array}{l}\text { Shifting the orientation of students' research data } \\
\text { collection }\end{array}$} \\
\hline 5 & Decrease in students' motivation & & \\
\hline 6 & Problems in internet signal & & \\
\hline
\end{tabular}

The 30 lecturers met the aforementioned purposing sampling criteria.

The current study deployed in-depth interviews to elicit detailed and contextual information about lecturers' perceptions of the difficulties associated with online thesis supervision. The data were analyzed using an interactive model [31]. Using this model, we conducted four stages of analysis: data collection, data condensation, data presentation, and drawing conclusion. As previously stated, data collection was conducted through in-depth interviews. To facilitate data presentation, data from interviews were grouped according to emerging representative themes. In terms of data presentation, the data were organized thematically. The data presentation was followed by a discussion of the data and our scientific interpretations to help make sense of it. Concerning the conclusion of the data, the data findings, discussions, and interpretations were comprehensively summarized in order to generate a representative conclusion.

\section{FINDINGS}

The data gathered from interviews about the complexities (problems and solutions) of online EFL thesis supervision can be categorized into a few themes. Table 1 illustrates the data summary.
According to table 1, the first problem was that some instructors were still getting acclimated to the offline-toonline transition of thesis supervision. In response to this circumstance, lecturer 14 stated the following, echoing the sentiments of others.

I frequently fail to open emails from students under my thesis supervision (interview with lecturer 14).

The second problem was that communication between instructors and students was relatively inefficient during online thesis supervision. For example, in agreement with others who made similar arguments, lecturer 17 stated the following.

My pupils and I have a lot of trouble with the style of communication. My pupils did not call me immediately away to address their problems. There might be two reasons for this. First, it is possible that this is related to pupils' diminished passion and earnestness. Second, this might be owing to the limits of internet communication technologies (interview with lecturer 17).

The third problem derived from lecturers' opinions was that lecturers did not always have time to access internet resources for online thesis supervision. Lecturer 2 stated the following in order to illustrate this condition among others that have comparable information.

I don't always have time to be active in front of my laptop, guiding or correcting my students' online theses, especially outside of campus events, which are, of course, jam-packed with other commitments (interview with lecturer 2).

The fourth problem that lecturers identified was that some of their students were impeded when collecting data in the field. For example, lecturer 5 provided the following information to represent others with comparable knowledge.

Based on my observations, the difficulty among my students is that they had previously planned to do 
field research, notably at schools before to the COVID-19 assault. The continuance of data collecting operations was impeded further after Indonesia was hit by the COVID-19 epidemic because access to schools was severely restricted, and the style of learning in schools was also converted to an online one (interview with lecturer $5)$.

For the sixth problem, the instructors perceived a decline in motivation among some of their pupils. For example, lecturer 23 stated the following to represent others.

The primary problem is that my students' enthusiasm and tenacity in finishing their thesis appear to have reduced after the thesis supervision method was changed to online (interview with lecturer 23).

Concerning the sixth problem, the instructors believed that the disruption in internet signals hampered the planned continuation of online thesis supervision. Lecturer 15 stated the following to represent others.

Students are occasionally impeded by the internet network, making online thesis supervision processes difficult (interview with lecturer 15).

The six problems with online thesis supervision described above are the lecturers' perspectives. According to the lecturers' opinions, these problems highlighted concerns on the side of both lecturers and students in terms of online thesis supervision.

The interviews were conducted on a continual basis in order to respond to the answers given by lecturers to the problems in online thesis supervision. The initial approach, according to table 1 , was to urge students to remind lecturers of the online supervision schedule. In agreement with others who shared comparable information, lecturer 19 stated the following.

I regularly ask the students under my thesis supervision to remind me of the online supervision schedule since I frequently forget the schedule owing to the abrupt shift of thesis supervision from face-to-face to online mode (lecturer 19).

The second option proposed by lecturers was to make active use of communication technologies. This approach was proposed by lecturers 6,8 , and 1 , as shown below.

I attempt to make use of ICT tools that may be used as a communication channel for online thesis supervision, such as making video chats with the Zoom program, Google Meet, or WA (lecturer 6).

To solve this, I assemble all of my students on a regular basis (often once a month) to meet traditionally through zoom. During the meeting, I ask what they have done so far this month and what their goals are for the following month. As a result, they may learn from one another and finally create desire to finish their thesis as soon as feasible (lecturer 8).

I record my recommendations and remarks on my students' theses and then email them the voice recordings. Corrections to students' thesis drafts using Microsoft Word track changes do not satisfy me, therefore I must submit more information and comments to students' theses via recording (lecturer 1).

The third solution proposed by lecturers was to assist students in interacting with authorized parties around the students' study goals. In order to represent others with comparable information, lecturer 22 stated the following.

I told my pupils right away to look for data sources that would be easy for them to access. For those who have already been unable to alter their research subjects, I help students in interacting with the schools where they will conduct their research, both individually and institutionally, so that the schools may aid my students in the procedures of gathering research data (lecturer 22).

The fourth solution proposed by the instructors was to change the direction of the students' study data collecting. This is seen in the following information provided by lecturer 17 .

I instruct my pupils to acquire data that is not too

difficult for them to collect. During supervision with me, I usually give my students the opportunity to collect data. Alternatively, I recommend that they gather data from schools whose instructors I am familiar with, so that I can assist them in alerting those teachers that my students would be collecting research data in their classes (lecturer 17).

The solutions proposed by the lecturers above appear to be consistent with the current online thesis supervision problems explored in the second part of study findings.

\section{DISCUSSION}

The current study was initiated to uncover the problems associated with online EFL undergraduate thesis supervision. It should be emphasized that this study was carried out in the midst of the covid-19 epidemic. First, our study indicated that some instructors were still getting acclimated to the offline-toonline transition of thesis supervision in this discourse. Second, communication between lecturers and students was relatively inefficient during online thesis supervision. The technology aspect of online thesis supervision introduced new complications in comparison to the face-to-face approach that instructors had become accustomed to. The offline-to-online transition of thesis supervision, similar to online learning, may result in ineffective interactions if technological competences and facilities are not met (Barclay et al., 2018; Thongsri et al., 2019). As a result, poor interactions may result in a failure to meet students' expectations and enhance students' negative opinions of lecturers [10]. Third, instructors did not always have the time to access internet material for online thesis supervision. The preceding was comparable to Ortiz-et Catalan's al. study, which revealed that one of the reasons why students' theses are of poor quality is a lack of supervision time. Another reason is a lack of efficient patterns underpinning thesis supervision processes [29]. 
Fourth, the lecturers reported that some of their students were impeded when collecting data in the field. The above problem arose since some of their students had previously planned to do field study before the covid-19 epidemic struck Indonesia. This pandemic struck in the midst of data gathering preparations. This problem then emerged, and pupils were affected. Fifth, the lecturers perceived a drop in motivation among some of their pupils. This might be related to the inefficient development of interactions as a result of the thesis supervision mode's offline-to-online transition. A similar problem happened in research conducted by Almeatani et al. [11]. Their research also suggested developing a portable mobile application to enhance successful lecturers' interactions. Sixth, the problem with internet signals hampered the planned continuance of online thesis supervision. This example is repeated in a study conducted by Pramana et al. on online learning in the Indonesian setting, where the volatility of internet signals frequently hampers the intended learning continuity [2].

The other set of findings from the current study focused on the solutions provided by lecturers to the problems in online thesis supervision. Based on the previous problems highlighted, the lecturers proposed some solutions, such as asking students to remind the lecturers of the online supervision schedule to solve forgetfulness problems; making active use of communication technology to build up effective interactions, improve students' motivation, and deal with students' internet problems; helping students to interact with the authorized parties of students' research objects; and shifting the orientation of students' research data collection. The solutions proposed by the lecturers are similar to those proposed in Casado-Lumbreras and Colomo-Palacios' study on online thesis supervision problems [28]. Their research described several strategies used by lecturers, including fostering students' active attitudes, effectively managing supervision time and planning the execution of thesis supervision, stimulating students' motivation, stimulating students' mental block management, reducing students' negative emotions, and assisting students who have difficulty identifying and developing their theses. Furthermore, difficulties such as restricted supervision time and scheduling conflicts between lecturers and students motivated academics such as Almeatani et al. and Nasution et al. to develop information systems to manage the thesis supervision procedures [11], [27]. The technologies developed are in the form of platforms that may be accessible via the cellphones of lecturers and students, with the convenience of interaction established.

This study successfully depicted the problems in online thesis supervision. As a result, knowledge about such difficulties might be used as vicarious experiences [34] by other relevant academicians, educators, and thesis lecturers in attempts to reflect on, predict, and address similar complexities connected to thesis supervision concerns.

\section{CONCLUSION}

In addressing the complexities of online EFL undergraduate thesis supervision, this study highlights a number of problems in online EFL thesis supervision based on the perspectives of lecturers in Central Java and Papua. Some of the problems include being in the process of adapting to the transformation of thesis supervision from an offline mode to an online mode, somewhat ineffective communication between lecturers and students, a lack of time available to always access online media, being hampered in the process of collecting field data, a decrease in student motivation, and internet problems. Following that, some solutions to problems in online thesis supervision are highlighted, such as asking students to remind lecturers of the online supervision schedule, actively using communication technology, assisting students in interacting with authorized parties of students' research objects, and shifting the orientation of students' research data collection. The answers provided by lecturers to difficulties encountered during online thesis supervision reflect their attempts to improve students' writing metacognition, self-efficacy, and growth mindsets.

It is suggested that more research be undertaken to address a similar problem as this study, but with more participants from various provinces in Indonesia. Such research might help us to expand on our current findings and contribute to the literature on online thesis supervision in the Indonesian setting. Such literature is still sparse in the Indonesian setting, and this gap presents an opportunity for in-depth scientific investigations.

\section{AUTHORS' CONTRIBUTIONS}

All authors have contributed to this study in a balanced manner.

\section{ACKNOWLEDGMENTS}

We would like to express our gratitude to all lecturer participants who have contributed to provide detailed data as desirable. We also thank Kementerian Pendidikan, Kebudayaan, Riset, dan Teknologi as the sponsor that has funded the completion of this study.

\section{REFERENCES}

[1] M. E. Osman, "Global impact of COVID-19 on education systems : the emergency remote teaching at Sultan Qaboos," J. Educ. Teach., pp. 1-9, 2020, doi: 10.1080/02607476.2020.1802583.

[2] C. Pramana et al., "Virtual learning during the covid-19 pandemic, a disruptive technology in higher education in indonesia," Int. J. Pharm. Res., vol. 12, no. 2, pp. 3209-3216, 2020, doi: 10.31838/IJPR/2020.12.02.430.

[3] L. Efriana, "Problems of online learning during covid-19 pandemic in EFL classroom and the solution," J. English Lang. Teach. Lit., vol. 2, no. 1, pp. 38-47, 2021.

[4] Q. Huang, "Comparing teacher's roles of F2f learning and online learning in a blended English 
course," Comput. Assist. Lang. Learn., vol. 32, no. 3, pp. 190-209, 2019, doi: 10.1080/09588221.2018.1540434.

[5] P. Gómez-Rey, E. Barbera, and F. FernándezNavarro, "Measuring teachers and learners' perceptions of the quality of their online learning experience," Distance Educ., vol. 37, no. 2, pp. 146-163, 2016, doi: 10.1080/01587919.2016.1184396.

[6] F. Martin, C. Wang, and A. Sadaf, "Student perception of helpfulness of facilitation strategies that enhance instructor presence, connectedness, engagement and learning in online courses," Internet High. Educ., vol. 37, no. March 2017, pp. 52-65, 2018, doi: 10.1016/j.iheduc.2018.01.003.

[7] C. Barclay, C. Donalds, and K. M. Osei-Bryson, "Investigating critical success factors in online learning environments in higher education systems in the Caribbean*," Inf. Technol. Dev., vol. 24, no. 3, pp. 582-611, 2018, doi: 10.1080/02681102.2018.1476831.

[8] N. Thongsri, L. Shen, and Y. Bao, "Investigating factors affecting learner's perception toward online learning: evidence from ClassStart application in Thailand," Behav. Inf. Technol., vol. 38, no. 12, pp. 1243-1258, 2019, doi: 10.1080/0144929X.2019.1581259.

[9] O. Gómez-Ortiz, E. M. Romera, and R. OrtegaRuiz, "Parenting styles and bullying. The mediating role of parental psychological aggression and physical punishment," Child Abus. Negl., vol. 51, pp. 132-143, 2016, doi: 10.1016/j.chiabu.2015.10.025.

[10] B. T. Agricola, F. J. Prins, M. F. van der Schaaf, and J. van Tartwijk, "Supervisor and student perspectives on undergraduate thesis supervision in higher education," Scand. J. Educ. Res., pp. 1-21, 2020, doi: 10.1080/00313831.2020.1775115.

[11] M. Almeatani, H. Alotaibi, E. Alasmari, M. Meccawy, and B. Alghamdi, "Thesis supervision mobile system for enhancing student-supervisor communication," Int. J. Interact. Mob. Technol., vol. 13, no. 6, pp. 4-14, 2019, doi: 10.3991/ijim.v13i06.9533.

[12] K. F. Weaver, V. Morales, M. Nelson, P. F. Weaver, A. Toledo, and K. Godde, "The benefits of peer review and a multisemester capstone writing series on inquiry and analysis skills in an undergraduate thesis," CBE Life Sci. Educ., vol. 15, no. 4, p. ar51.1-ar51.9, 2016, doi: 10.1187/cbe.16-01-0072.

[13] C. M. Kiriakos and J. Tienari, "Academic writing as love," Manag. Learn., vol. 49, no. 3, pp. 263277, 2018, doi: 10.1177/1350507617753560.

[14] A. Ansarifar, H. Shahriari, and R. Pishghadam, "Phrasal complexity in academic writing: A comparison of abstracts written by graduate students and expert writers in applied linguistics," J. English Acad. Purp., vol. 31, pp. 58-71, 2018, doi: 10.1016/j.jeap.2017.12.008.
[15] A. Cumming, C. Lai, and H. Cho, "Students' writing from sources for academic purposes: A synthesis of recent research," J. English Acad. Purp., vol. 23, pp. 47-58, 2016, doi: 10.1016/j.jeap.2016.06.002.

[16] S. Ebadi and M. Rahimi, "An exploration into the impact of WebQuest-based classroom on EFL learners' critical thinking and academic writing skills: a mixed-methods study," Comput. Assist. Lang. Learn., vol. 31, no. 5-6, pp. 617-651, Jul. 2018, doi: 10.1080/09588221.2018.1449757.

[17] D. Wu, W. Dang, D. He, and R. Bi, "Undergraduate information behaviors in thesis writing: A study using the Information Search Process model," J. Librariansh. Inf. Sci., vol. 49, no. 3, pp. 256-268, 2017, doi: $10.1177 / 0961000616654960$.

[18] A. I. Moreno and J. M. Swales, "Strengthening move analysis methodology towards bridging the function-form gap," English Specif. Purp., vol. 50, pp. 40-63, 2018, doi: 10.1016/j.esp.2017.11.006.

[19] M. Huerta et al., "Graduate students as academic writers: writing anxiety, self-efficacy and emotional intelligence," High. Educ. Res. Dev., pp. 1-14, 2016, doi: 10.1080/07294360.2016.1238881.

[20] A. D. Gedamu, "TEFL graduate supervisees' views of their supervisors' supervisory styles and satisfaction with thesis supervision," Iran. J. Lang. Teach. Res., vol. 6, no. 1, pp. 63-74, 2018.

[21] Y. Teklesellassie, "Views of summer TEFL postgraduate students and their supervisors on the practice of thesis supervision in the Ethiopian context," Pasaa, vol. 58, pp. 131-165, 2019.

[22] K. Filippou, J. Kallo, and M. Mikkilä-Erdmann, 'Students' views on thesis supervision in international master's degree programmes in Finnish universities," Intercult. Educ., vol. 28, no. 3, pp. 334-352, 2017, doi: 10.1080/14675986.2017.1333713.

[23] Y. (Olivia) Zhang and K. Hyland, "Advice-giving, power and roles in theses supervisions," $J$. Pragmat., vol. 172, pp. 35-45, 2021, doi: 10.1016/j.pragma.2020.11.002.

[24] F. Strebel, S. Gürtler, B. Hulliger, and J. Lindeque, "Laissez-faire or guidance? Effective supervision of bachelor theses," Stud. High. Educ., vol. 46, no. 4, pp. 866-884, 2021, doi: 10.1080/03075079.2019.1659762.

[25] T. Karunaratne, "Blended supervision for thesis projects in higher education: A case study," Electron. J. e-Learning, vol. 16, no. 2, pp. 79-90, 2018.

[26] U. R. Averweg, "Enabling role of an intranet to augment e-coaching," Ind. Commer. Train., vol. 42, no. 1, pp. 47-52, 2010, doi: 10.1108/00197851011013715.

[27] T. H. Nasution, F. Pratama, K. Tanjung, I. Siregar, and A. Amalia, "Online thesis guidance management information system," J. Phys. Conf. Ser., vol. 978, no. 1, pp. 1-7, 2018, doi: 
10.1088/1742-6596/978/1/012081.

[28] C. Casado-Lumbreras and R. Colomo-Palacios, "Online coaching in thesis supervision: A qualitative study," ACM Int. Conf. Proceeding Ser., pp. 489-495, 2014, doi: $10.1145 / 2669711.2669944$.

[29] M. Ortiz-Catalan, A. Middleton, and M. Gustafsson, "Supervision of M.Sc. theses using the writing of a scientific article as a framework to increase efficiency and quality of research outcomes," Proc. Annu. Int. Conf. IEEE Eng. Med. Biol. Soc. EMBS, pp. 1436-1439, 2019, doi: 10.1109/EMBC.2019.8856364.

[30] U. Malaga-Toboła, I. Boulven, S. Kocira, A. Szparaga, and A. Henri, "The use of information sources and online databases for writing theses by students of selected studies," E3S Web Conf., vol. 132, pp. 3-8, 2019, doi: $10.1051 /$ e3sconf/201913201017.
[31] M. B. Miles, A. M. Huberman, and J. Saldana, Qualitative data analysis: A methods sourcebook. Thousand Oaks, California 91320: SAGE Publications, Inc., 2014.

[32] C. Barclay, C. Donalds, and K. M. Osei-Bryson, "Investigating critical success factors in online learning environments in higher education systems in the Caribbean," Inf. Technol. Dev., vol. 24, no. 3, pp. 582-611, 2018, doi: 10.1080/02681102.2018.1476831.

[33] N. Thongsri, L. Shen, and Y. Bao, "Investigating factors affecting learner's perception toward online learning: evidence from ClassStart application in Thailand," Behav. Inf. Technol., vol. 38, no. 12, pp. 1243-1258, 2019, doi: 10.1080/0144929X.2019.1581259.

[34] A. Bandura, "On the functional properties of perceived self-efficacy revisited," J. Manage., vol. 38, pp. 9-44, 2012. 